\title{
Thermal Biology of an Iguanian Lizard, Oplurus cuvieri cuvieri, in a Tropical Dry Forest of Madagascar
}

\author{
HERILALA J. A. R. RANDRIAMAHAZO ${ }^{1,2}$ AND AKIRA MORI ${ }^{1 *}$ \\ ${ }^{1}$ Department of Zoology, Graduate School of Science, Kyoto University, Sakyo, Kyoto 606- \\ 8502, JAPAN \\ 2 Present address: WCS Madagascar, BP 8500, Antananarivo 101, MADAGASCAR
}

\begin{abstract}
Thermal characteristics of an Iguanian lizard, Oplurus cuvieri cuvieri, were examined in a tropical dry forest of northwestern Madagascar. This lizard is an arboreal, strictly diurnal sit-and-wait predator feeding mostly on insects. A field study was conducted from mid-September 1997 to midJanuary 1998 and from late-September to mid-November 1998. Ambient air temperature significantly affected body temperature, but sex, snout-vent length, month, perching height, and posture of perching lizards did not show significant effects on body temperature. Effects of time and interaction between ambient temperature and time were significant in the first half of 1997 (dry season) and 1998, but not in the latter half of 1997 . Overall body temperature was significantly correlated with ambient temperature, and slopes between them did not significantly deviate from one. However, slopes varied with time of day, and significant correlation between ambient and body temperatures diminished in the midday period. Body temperature was significantly higher than corresponding ambient temperature. In the rainy season, when ambient temperature decreases, the lizards seemed to regulate its body temperature to some extent by selecting hotter microhabitat (the ground). Collectively, although the study site is a relatively open, deciduous forest, where direct solar radiation for thermoregulation by basking is available, $O$. c. cuvieri exhibits intermediate features between thermoregulator and thermoconformer, having mixed characteristics of both types.
\end{abstract}

Key words: Madagascar; Oplurus cuvieri cuvieri; Iguania; Body temperature; Tropical dry forest

\section{INTRODUCTION}

In lizards thermal conditions can modify activity periods, which in turn, influence their life histories (Grant and Dunham, 1990).

* Corresponding author. Tel: +81-75-753-4075;

Fax: +81-75-753-4075; E-mail address: gappa @ethol.zool.kyoto-u.ac.jp
Thermal conditions can also interact with the physiological performance and influence the ecological distribution of species (Gorman and Hillman, 1977; Huey, 1982). Basically, a particular lizard species selects microhabitats that are both thermally and structurally suited to its physiological, morphological, and behavioral traits. For example, many lizards have a relatively narrow range of preferred body 
temperatures, which often corresponds to various physiological optima (Bennett, 1980; Huey, 1982). Similarly, lizards exhibit distinct preferences for particular substrates, perch heights, vegetation densities or other aspects of habitat structure depending on the thermal environment (Ruibal, 1961; Williams, 1983). Consequently, to compromise with various thermal demands and preference for structural habitats, lizards, especially diurnal species, exhibit various modes of behavioral thermoregulation.

Nonetheless, the vast majority of the available data on lizard thermoregulation are gleaned primarily from studies of temperatezone species, where high daily fluctuation of ambient temperatures induces a lizard to devote considerable time and effort to thermoregulation if it attempts to maintain high and stable body temperatures (Avery, 1982). Contrary to temperate zones, in tropical forests, temporal and spatial variations in environmental temperatures may not have much influence on an animal's activities because the relatively benign environmental temperatures permit extensive thermoconformity (Avery, 1982; Shine and Madsen, 1996).

Most studies on thermal biology of lizards in tropical forests have been based on small diurnal species (e.g., Inger, 1959; Alcala and Brown, 1966), the group for which behavioral thermoregulation is likely to be most important because of their generally small body size combined with high diurnal thermal heterogeneity. The other tropical lizards that have been studied in this respect are those living in environments of low thermal heterogeneity such as densely vegetated forests (Avery, 1982; Rummery et al., 1994), where the opportunities for behavioral regulation of body temperatures are very limited. In such a habitat, many species have proved to be thermoconformers, that is, thermally passive animals, with little overt thermoregulatory behavior (Ruibal, 1961; Huey and Webster, 1976; Tanaka, 1986; Hertz et al., 1993). However, modes of thermoregulation are not always matched to the apparent thermal habitats.
For example, Mori and Hikida (1993) showed the thermal passivity of a flying lizard, Draco volans, living in an open habitat of tropical Borneo, where direct solar radiation is readily available for lizards. In addition, an arboreal skink, Apterygodon vittatus inhabiting the same study area as the flying lizard, showed thermal conditions intermediate between baskers and nonbaskers (Mori et al., 1995). Similar intermediate or partial basking behavior has been reported in a few other lizard species in the tropics (Avery, 1982).

In the present paper, we investigated the thermal biology of an Iguanian lizard, Oplurus cuvieri cuvieri, living in a tropical dry deciduous forest of Madagascar. This species is a medium-sized (mean body mass in males and females are $147 \mathrm{~g}$ and $84 \mathrm{~g}$, respectively; Randriamahazo, 2000), arboreal, and strictly diurnal lizard inhabiting relatively open forests. Although earlier studies of $O$. c. cuvieri suggested the presence of thermal preference of this lizard (Randriamahazo, 1998) and the absence of sexual differences in body temperature (Randriamahazo and Mori, 1999), morphological, behavioral, and environmental attributes that could affect the thermal biology of lizards were not adequately examined. Here, we characterized the thermal features of O. c. cuvieri by examining the effects of sex, size, month, time of day, perch height, and posture that are the potential source of variations in its body temperature.

\section{MATERIALS AND METHODS}

Oplurus c. cuvieri is an endemic iguanian lizard of Madagascar (Glaw and Vences, 1994). This sit-and-wait insectivorous lizard is primarily arboreal, spending much of its time perching on tree trunks or fallen logs (Randriamahazo and Mori, 1999; Mori and Randriamahazo, 2002), although it occasionally moves on the ground for reproductive activity such as egg laying and territorial activity (Randriamahazo and Mori, 1999, 2001). Inactive lizards are found sheltering inside naturally sculptured hollows of stumps, 
dead logs, and live trees (Blanc, 1977; Randriamahazo and Mori, 1999).

The study was conducted at the forest of Ampijoroa, Ankarafantsika Strict Nature Reserve (since 7 August 2002 part of Ankarafantsika, including Ampijoroa, is designated as a National Park), located in northwestern Madagascar $\left(16^{\circ} 15^{\prime} \mathrm{S}\right.$ and $\left.46^{\circ} 48^{\prime} \mathrm{E}\right)$. The study site is a ca. $1 \mathrm{~km} \times 1 \mathrm{~km}$ dry deciduous forest having irregularly extended main paths (width $=2-4 \mathrm{~m}$ ) in it. A plot of approximately 16.6 ha (Jardin Botanique A) subdivided into ca. $5 \mathrm{~m} \times 5 \mathrm{~m}$ subplots by narrow trails (width $=0.5-1.5 \mathrm{~m}$ ) is present in the western area of the study site. All trails are human-made, and large trails are regularly maintained for tourism purposes. The elevation is approximately $200 \mathrm{~m}$ asl. The vegetation is dominated by three species of Strichnos trees generally 9-12 $\mathrm{m}$ in height (Razafy, 1987; Urano et al., 1994), and scattered shrubs and open areas with abundant leaf litter are present. The climate is mainly dominated by a rainy season from November to March and a dry season from April to October. In the dry season, most trees shed their leaves, making sunlight-rich, open understory and a forest floor with leaf litter. As the rainy season progresses, new leaves grow and the canopy cover increases, reducing the availability of solar radiation reaching the forest floor, although the main paths still provide sunlightrich habitats (see a photograph in Mori et al, in press).

We collected lizards found outside their shelter trees mainly in the Jardin Botanique A throughout the daylight hours (between $0700 \mathrm{~h}$ and $1800 \mathrm{~h}$ ) from 17 September 1997 to 15 January 1998 (hereafter referred to as year 1997) and from 29 September 1998 to 18 November 1998 (year 1998). Daily precipitation and daily maximum and minimum temperatures recorded at the study site during these periods are presented in Randriamahazo and Mori (2001). Within $10 \mathrm{~s}$ of capture of a lizard by noosing we measured its cloacal body temperature (BT; to the nearest $0.1 \mathrm{C}$ ) and ambient air temperature at $1 \mathrm{~m}$ off the ground in shade (AT) with a quick-reading mercury thermometer (Schultheis). Care was taken to prevent temperature from being influenced by handling, and all lizards requiring extensive efforts to capture were excluded from the following analyses. We recorded the time of day, predominant orientation of lizards' body (posture: horizontal, upward vertical, or downward vertical), and perch height of lizards above the ground. Based on preliminary observations, the vertical position with head facing downward may represent a readiness to chase after a prey item or an unwelcome intruder, whereas the head facing upward may indicate an alert posture related to basking or general survey of the home range area (Randriamahazo, unpublished data). We also measured the snout-vent length of lizards (SVL; to the nearest $1 \mathrm{~mm}$ ). We assigned each captured lizard to adult males, adult females, or juveniles based on the criteria in Randriamahazo (2000). Lizards were marked individually by toe clipping, color painting, and passive integrated transponder (PIT) and released at the site of capture as soon as possible.

In the following analyses of BT, lizards that were perching stationary on substrate, such as trees, logs, and ground, were examined, and those actively moving, such as chasing, digging (for laying eggs), and running on the ground, were excluded to remove the possible temporary effects of reproductive activities on BT. Because some individuals were collected in both years, the following statistical analyses were conducted for each year separately to ensure the statistical independence of the data. In each year, each individual was contributed to only one dataset. The data used in the present study included some data used for the analysis of sexual differences of BT in Randriamahazo and Mori (1999). The difference of the dataset between these studies is due to the different objectives of the studies.

To determine factors that affect BT, we first conducted analysis of covariance (ANCOVA) 
with AT and SVL as covariates, month and sex (male, female, juvenile) as factors, and BT as a dependent variable. Interactions between AT and month and between AT and sex were included in this ANCOVA model. Because, except for AT, no significant effects were detected (see Results), further ANCOVA was conducted with AT as covariate, time, perch height, and posture as factors, and BT as a dependent variable. Interaction between AT and time was included in this model. For this analysis both time and perch height were divided into five categories (time; 7-9, 9-11, 11-13, 13-15, and 15-18: perch height; $0 \mathrm{~cm}$, $1-50 \mathrm{~cm}, 51-100 \mathrm{~cm}, 101-150 \mathrm{~cm}$, and $>150$ $\mathrm{cm})$. The data of 1997 were divided into two periods (data before 19 November, which is comparable to the study period of 1998 and approximately to the dry season, and those after 18 November) and analyzed separately. For comparisons of BT and AT among months and among time categories, onefactor analysis of variance (ANOVA) was used followed by multiple comparisons (TukeyKramer method). Regression analysis was made with Pearson correlation coefficient. Differences between AT and BT were tested using a paired t-test. ANCOVA was conducted using JMP 3.2.2 (1997). The other statistical analyses were conducted using StatView 5.0 (1998). All of the analyses were tested for statistical significance at the $\mathrm{P}<0.05$ level.

\section{RESUlts}

In 1997 mean $\mathrm{BT} \pm \mathrm{SE}$ of males, females, and juveniles was $35.4 \pm 0.4,36.6 \pm 0.4$, and $35.7 \pm 0.5$, respectively, and in 1998 it was $37.3 \pm 0.7,36.8 \pm 0.3$, and $37.5 \pm 0.4$, respectively. The first test with ANCOVA revealed that only AT significantly affected BT in both years although sex and interaction between AT and sex were close to a significant level in 1998 (Table 1). Hence, relationships between AT and BT were examined with all sexes and months combined. BT was significantly correlated with AT in both years $(1997, \mathrm{r}=0.64$, $\mathrm{df}=1,204, \mathrm{~F}=139.4, \mathrm{P}<0.0001 ; 1998, \mathrm{r}=$ $0.73, \mathrm{df}=1,125, \mathrm{~F}=140.7, \mathrm{P}<0.0001$; Fig. 1). Slopes of regression lines between AT and BT were significantly different from 0 (1997, slope $=0.898, \mathrm{t}=11.8, \mathrm{P}<0.0001 ; 1997$, slope $=$ $0.997, \mathrm{t}=11.7, \mathrm{P}<0.0001)$, but their $95 \%$ confidence intervals overlapped with 1 in both years (1997, 0.748-1.048; 1998, 0.831-1.164). Overall mean AT and BT in 1997 were $31.8 \pm 0.2$ and $35.8 \pm 0.2$, respectively, and were $33.4 \pm 0.2$ and $37.1 \pm 0.2$ in 1998. BT was significantly higher than the corresponding AT in both years $(1997, \mathrm{df}=205, \mathrm{t}=20.8, \mathrm{P}<$ $0.0001 ; 1998, \mathrm{df}=126, \mathrm{t}=22.0, \mathrm{P}<0.0001)$.

To analyze the monthly variation in temperatures we used only the data of 1997, which were collected during a more extended period than the data of 1998 . AT significantly varied among months $(\mathrm{df}=4,201, \mathrm{~F}=8.8, \mathrm{P}<0.0001$; Fig. 2). Generally, AT was high in the dry

TABLE 1. Results of the initial test with analysis of covariance for body temperature of Oplurus cuvieri cuvieri.

\begin{tabular}{|c|c|c|c|c|c|c|}
\hline \multirow[b]{2}{*}{ Source of variation } & \multicolumn{3}{|c|}{1997} & \multicolumn{3}{|c|}{1998} \\
\hline & $\mathrm{df}$ & $\mathrm{F}$ & $\mathbf{P}$ & $\mathrm{df}$ & F & $P$ \\
\hline Ambient temperature (AT) & 1 & 110.18 & $<0.001^{*}$ & 1 & 9.50 & $0.003^{*}$ \\
\hline Snout-vent length & 1 & 0.11 & 0.737 & 1 & 0.10 & 0.754 \\
\hline Sex & 2 & 2.11 & 0.124 & 2 & 3.00 & 0.054 \\
\hline Month & 4 & 1.98 & 0.100 & 2 & 0.15 & 0.861 \\
\hline $\mathrm{AT} \times \operatorname{sex}$ & 2 & 1.59 & 0.206 & 2 & 3.01 & 0.053 \\
\hline AT $\times$ month & 4 & 1.89 & 0.114 & 2 & 0.10 & 0.901 \\
\hline
\end{tabular}

* Significant at $\mathrm{P}<0.05$ level. 

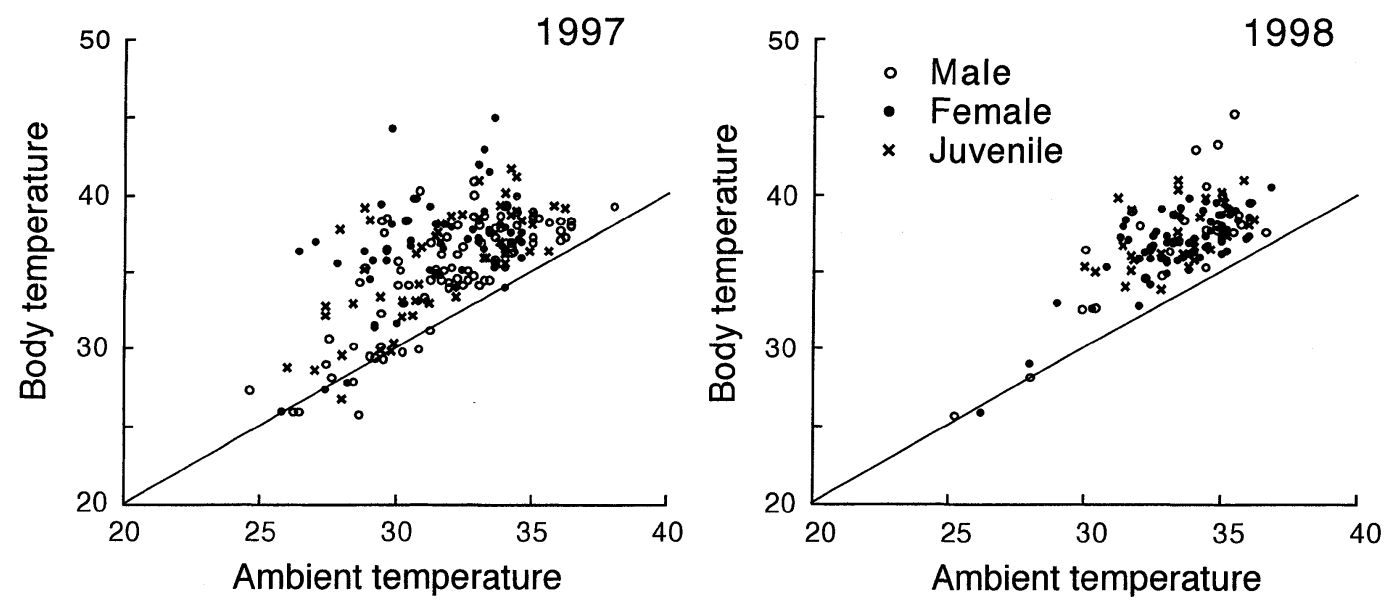

FIG. 1. Relationship between ambient air temperature and cloacal body temperature in males, females, and juveniles of Oplurus cuvieri cuvieri recorded in two study periods (1997 and 1998).



FIG. 2. Monthly variations in ambient air temperature and cloacal body temperature of Oplurus cuvieri cuvieri. Mean $\pm 1 \mathrm{SE}$ are presented. Same lowercase letters above bars denote means that do not differ significantly based on pairwise multiple comparisons among months. Statistical comparisons between ambient and body temperatures for each month were not made.

season (September) and became lower in the rainy season (December and January). By contrast, BT did not vary significantly among months $(\mathrm{df}=4,201, \mathrm{~F}=1.0, \mathrm{P}=0.403$; Fig. 2 )
The second test with ANCOVA yielded similar results in 1998 and the first half of 1997, showing significant effects in AT, time, and interaction between AT and time (Table 
2). On the other hand, in the second half of 1997 only AT showed significant effects (Table 2). The relationships between AT and BT separated by time are presented in Fig. 3. In 1998 and the first half period of 1997 BT was significantly correlated with AT in each time category except for 13-15. Comparisons of $95 \%$ confidence intervals of each slope indicated that the above significant interaction effects between AT and time in 1998 are attributable to the higher slope in the 7-9 time category than in the 15-18 time category, and those in the first half of 1997 are attributable to the higher slopes in 7-9 and 9-11 than in 11-13 and the higher slope in 9-11 than in 15-18 (Table 3). In the latter half of 1997 significant correlations between AT and BT were observed only in 11-13 and 15-18 time categories, in which slopes of regression lines were not significantly different from each other (Table 3).

In each year both AT and BT significantly varied among time (first half of 1997, AT, $\mathrm{df}=4,125, \mathrm{~F}=22.9, \mathrm{P}<0.0001, \mathrm{BT}, \mathrm{df}=4$, $125, \mathrm{~F}=11.0, \mathrm{P}<0.0001$; second half of 1997 , AT, $\mathrm{df}=4,66, \mathrm{~F}=8.6, \mathrm{P}<0.0001, \mathrm{BT}, \mathrm{df}=4$, $66, \mathrm{~F}=2.9, \mathrm{P}=0.028 ; 1998, \mathrm{AT}, \mathrm{df}=4,120$, $\mathrm{F}=21.0, \mathrm{P}<0.0001, \mathrm{BT}, \mathrm{df}=4,120, \mathrm{~F}=6.8$, $\mathrm{P}<0.0001$; Fig. 4). Generally, fluctuating patterns of BT paralleled those of AT. However, the results of pairwise multiple comparisons suggested that AT varied more extensively than BT in 1998 and the first half of 1997, which was reflected as the significant effects of

TABLE 2. Results of the second test with analysis of covariance for body temperature of Oplurus cuvieri cuvieri.

\begin{tabular}{|c|c|c|c|c|c|c|c|c|c|}
\hline \multirow[b]{2}{*}{ Source of variation } & \multicolumn{3}{|c|}{1997 (before 19 Nov) } & \multicolumn{3}{|c|}{1997 (after 18 Nov) } & \multicolumn{3}{|c|}{1998} \\
\hline & df & $\mathrm{F}$ & $\mathbf{P}$ & df & $\mathrm{F}$ & $\mathbf{P}$ & df & F & $\mathrm{P}$ \\
\hline Ambient temperature (AT) & 1 & 80.42 & $<0.001 *$ & 1 & 16.86 & $<0.001 *$ & 1 & 70.45 & $<0.001 *$ \\
\hline Time & 4 & 5.61 & $<0.001 *$ & 4 & 0.24 & 0.914 & 4 & 5.22 & $<0.001 *$ \\
\hline Perch height & 4 & 0.89 & 0.475 & 4 & 2.06 & 0.099 & 4 & 1.83 & 0.128 \\
\hline Posture & 2 & 1.91 & 0.153 & 2 & 0.39 & 0.677 & 2 & 2.86 & 0.062 \\
\hline AT $\times$ time & 4 & 5.67 & $<0.001 *$ & 4 & 0.25 & 0.908 & 4 & 5.67 & $<0.001^{*}$ \\
\hline
\end{tabular}

* Significant at $\mathrm{P}<0.05$ level.

TABLE 3. Results of regression analysis between ambient temperature and body temperature of Oplurus cuvieri cuvieri for each time category. Figures in parentheses are $95 \%$ confidence intervals of slopes.

\begin{tabular}{|c|c|c|c|c|c|c|c|c|c|c|c|c|}
\hline \multirow[b]{2}{*}{ Time of day } & \multicolumn{4}{|c|}{1997 (before 19 Nov) } & \multicolumn{4}{|c|}{1997 (after 18 Nov) } & \multicolumn{4}{|c|}{1998} \\
\hline & $\mathrm{n}$ & $\mathrm{r}$ & $P$ & Slope & $\mathrm{n}$ & $\mathrm{r}$ & $\mathrm{P}$ & Slope & $\mathrm{n}$ & $\mathrm{r}$ & $\mathbf{P}$ & Slope \\
\hline \multirow[t]{2}{*}{$7-9$} & 13 & 0.76 & $0.003^{*}$ & 1.85 & 8 & 0.42 & 0.299 & - & & 0.94 & $0.006^{*}$ & 3.22 \\
\hline & \multicolumn{4}{|r|}{$(0.80-2.91)$} & & & & & \multicolumn{4}{|r|}{$(1.56-4.87)$} \\
\hline \multirow[t]{2}{*}{$9-11$} & 29 & 0.83 & $<0.001^{*}$ & 1.61 & 21 & 0.41 & 0.066 & - & 23 & 0.83 & $<0.001 *$ & 1.63 \\
\hline & \multicolumn{4}{|r|}{$(1.19-2.04)$} & & & & & \multicolumn{4}{|r|}{$(1.14-2.13)$} \\
\hline \multirow{2}{*}{$11-13$} & 32 & 0.42 & $0.017 *$ & 0.43 & 19 & 0.61 & $0.005 *$ & 1.13 & 28 & 0.48 & $0.010^{*}$ & 0.98 \\
\hline & \multicolumn{4}{|c|}{$(0.08-0.77)$} & \multicolumn{4}{|c|}{$(0.39-1.88)$} & \multicolumn{4}{|r|}{$(0.25-1.70)$} \\
\hline $13-15$ & 11 & 0.32 & 0.331 & - & 8 & 0.62 & 0.103 & - & 21 & 0.27 & 0.243 & - \\
\hline \multirow[t]{2}{*}{$15-18$} & 45 & 0.83 & $<0.001^{*}$ & 0.81 & 15 & 0.61 & $0.015^{*}$ & 1.01 & 47 & 0.86 & $<0.001 *$ & 1.02 \\
\hline & \multicolumn{4}{|c|}{$(0.64-0.97)$} & \multicolumn{4}{|c|}{$(0.23-1.80)$} & \multicolumn{4}{|r|}{$(0.84-1.20)$} \\
\hline
\end{tabular}

* Significant at $\mathrm{P}<0.05$ level. 

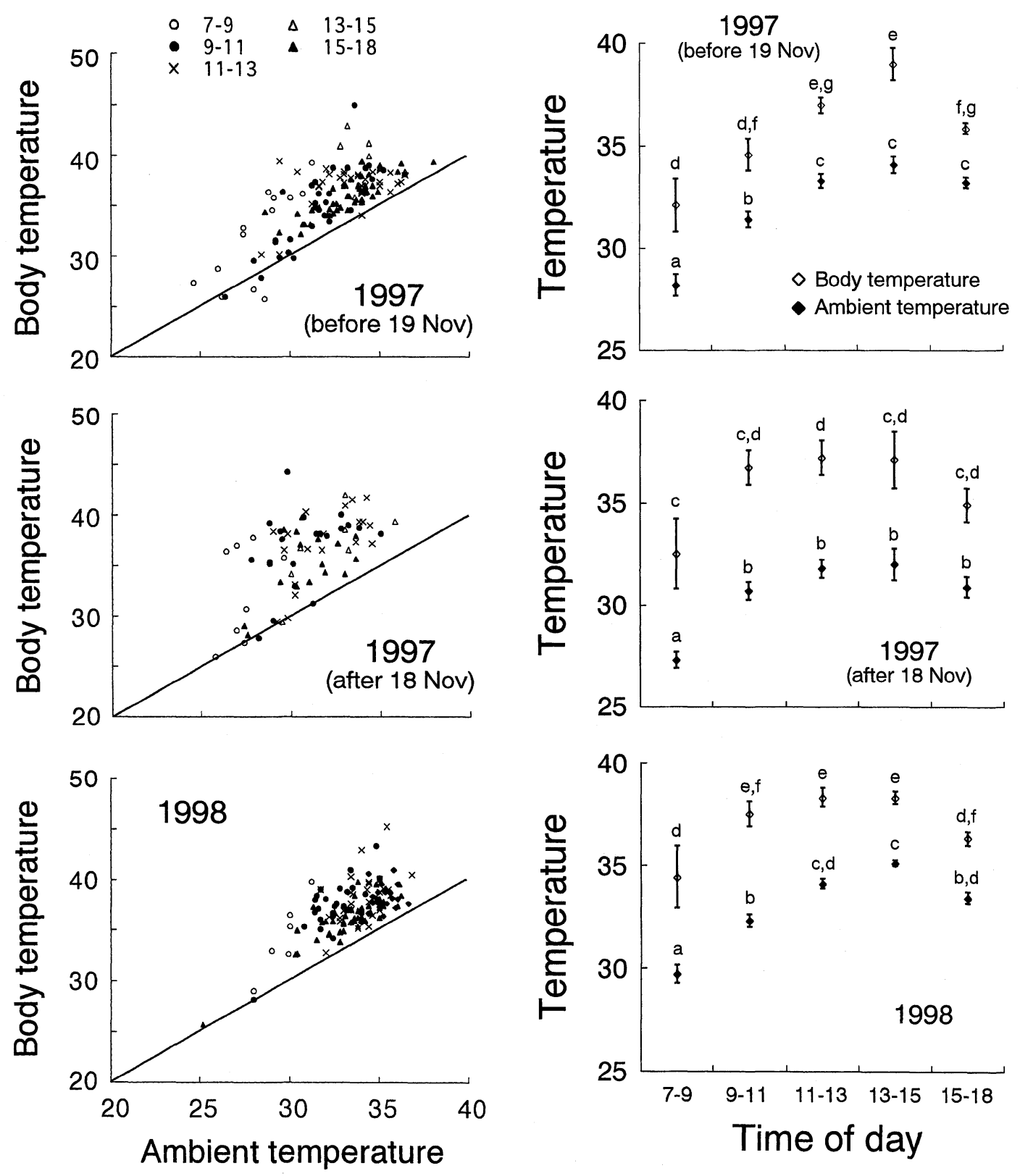

FIG. 3. Relationships between ambient air temperature and cloacal body temperature of Oplurus cuvieri cuvieri separately shown for five time categories.

FIG. 4. Daily variations of ambient air temperature and cloacal body temperature of Oplurus cuvieri cuvieri. Means $\pm 1 \mathrm{SE}$ are presented. Same lowercase letters above bars denote means that do not differ significantly based on pairwise multiple comparisons among time categories. Statistical comparisons between ambient and body temperatures for each time category were not made. 
interaction between $\mathrm{AT}$ and time in the above ANCOVA,

\section{DISCUSSION}

Unlike typical tropical rainforests, where closed vegetation precludes efficient thermoregulation by lizards, tropical dry forests such as the present study site (Ampijoroa) would provide lizards with much opportunity for strict themoregulation. In the Ampijoroa forest, predominant deciduous trees lose their leaves during a long dry season from April to October, and solar radiation for thermoregulation of lizards dwelling in the forest is available every day. As the rainy season begins around the end of October, new leaves grow and canopy cover increases. This physical barrier along with frequent cloudy or rainy climatic conditions reduce, both temporally and spatially, the amount of sunny spots available to the lizards on the forest floor and understory of the forest, especially after midrainy season around December to January. Nevertheless, the abundance of forest edges along complex artificial paths still provides open microhabitats for thermoregulation even during the rainy season. Therefore, it seems that in the Ampijoroa forest effective thermoregulation is potentially possible for lizards throughout the year.

The results of the present study suggest mixed features of thermoregulator and thermoconformer in $O$. c. cuvieri. The relatively broad range of BT, moderately significant correlation of BT with AT, and slopes of regression lines between $\mathrm{AT}$ and $\mathrm{BT}$ that do not significantly deviate from 1 are characteristics of a thermoconformer (Avery, 1982). The daily fluctuating pattern of BT corresponding to that of AT also suggests a thermally passive feature of the lizard. The absence of differences in BT between the sexes and between adults and juveniles may reflect the unimportance of thermoregulation in this lizard, although comparisons of BT between gravid and non-gravid females are desirable.

On the other hand, the relatively constant
BT over months and less fluctuating daily BT compared to AT imply active thermoregulation by $O$. c. cuvieri. The relatively higher slopes of the regression lines between AT and $\mathrm{BT}$ in the morning and non-significant correlations between them during the midday in the dry season (1998 and the first half of 1997) also imply the occurrence of thermoregulatory behavior. Actually, the lizards often perched in sunlight: in 182 out of 413 sightings the lizard was perching in sunlight (Randriamahazo and Mori, 1999). The relatively constant monthly BT may have been maintained by the selection of sunlight-rich microhabitat, especially in December and January, when average AT and maximum daily air temperature of the study site decreased (see Randriamahazo and Mori, 2001 for the latter data). Comparisons of the perching height frequency among months of the first study period support this idea: $O$. c. cuvieri more frequently perched on the ground in the rainy season than in the dry season (September \& October vs. November, $\chi^{2}=26.3, \mathrm{P}<0.0001$; September $\&$ October vs. December \& January, $\chi^{2}=39.3, \mathrm{P}<0.0001$; Table 4). Based on a close examination of Fig. 1 , BT seems to have a maximum set point temperature at approximately $40 \mathrm{C}$, suggesting thermoregulating behavior of the lizard to maintain its BT at a preferred maximum level. A few individuals showing extremely high BT ( $>41 \mathrm{C}$ ) may have been females just finished egg-laying on the sunny sandy trails (Randriamahazo and Mori, 2001) or males just after chasing or fighting with intruders (Randriamahazo and Mori, 1999) although we used only stationary individuals in the present analyses. Definitive determination of the

TABLE 4. Seasonal differences in the number of lizards for each perch height class.

\begin{tabular}{lrrrcc}
\hline \multirow{2}{*}{ Month } & \multicolumn{5}{c}{ Perch Height (cm) } \\
\cline { 2 - 6 } & 0 & $1-50$ & $51-100$ & $101-150$ & $>150$ \\
\hline Mid-Sep to Oct & 3 & 44 & 34 & 8 & 5 \\
Nov & 19 & 16 & 20 & 3 & 2 \\
Dec to mid-Jan & 19 & 7 & 11 & 6 & 4 \\
\hline
\end{tabular}


occurrence of thermoregulation requires tests of biophysical models as well as direct observations of thermoregulatory behaviors (Hertz et al., 1993).

Recently, Akani et al. (2002) stressed that one important contribution of thermoregulation in tropical reptiles is, as has been pointed out for lizards inhabiting hot desert environments (Avery, 1982), the avoidance of excessively high temperature, rather than the increase of body temperature to the preferred level. A study on the Madagascan day gecko, Phelsuma madagascariensis kochi, which was conducted in the same area of the Ampijoroa forest as in the present study, showed that the gecko is basically thermally passive, but it seems to decrease its BT when AT is higher than $30 \mathrm{C}$ (Ikeuchi et al., in press). In contrast, BT of $O$. c. cuvieri was always higher than immediate AT except for a few cases when AT was lower than $30 \mathrm{C}$. Considering the ecological features common to these two syntopic species, that is, arboreal, diurnal, and insectivorous habits (Ikeuchi et al., in press; Mori et al., in press), it is interesting that the two species have quite different thermal propensities. A segregation of thermal propensity into baskers and nonbaskers has been reported in sympatric skink species in tropical forests (e.g., Inger, 1959; Fitch, 1973). The differences in thermal niche between $O$. c. cuvieri and $P$. madagascariensis kochi may enable their coexistence, because otherwise they have a very similar ecological niche. Thermal characteristics of other syntopic, diurnal, arboreal, insectivorous lizards, that is, chameleons of the genus Furcifer, as well as coexisting terrestrial lizards, such as Mabuya elegans (Scincidae) and Zonosaurus laticaudatus (Gerrhosauridae) (Mori et al., in press), are worth investigating to reveal the diversity of thermal strategies among syntopic lizards, which may be associated with the variability of costs and benefits of thermoregulation (Huey and Slatkin, 1976). Comparisons of their thermal strategies would clarify the mechanism of thermal niche segregation among tropical lizards co-inhabiting a dry deciduous forest (Randriamahazo, 1998).

\section{ACKNOWLEDGMENTS}

We are grateful to S. Yamagishi for providing the opportunity to conduct this study and Bruno R. for his assistance in the field. We also thank the staff of Parc Botanique et Zoologique de Tsimbazaza, l'Association Nationale pour la Gestion des Aires Protégées, and Conservation International for their cooperation in conducting this research. This study was financially supported by a Grant-in-Aid under the Monbusho International Scientific Research Program (Field Research, no. 06041093). The data analyses were partially supported by a grant for the Biodiversity Research of the 21st Century COE (A14).

\section{LITERATURE CITED}

AKani, G. C., E. A. Eniang, I. J. EKro, F. M. ANGELICI, AND L. LUISELLI. 2002. Thermal and reproductive ecology of the snake Psammophis phillipsi from the rainforest region of southern Nigeria. Herpetol. J. 12: 63-67.

AlCAlA, A. C. AND W. C. BROWN. 1966. Thermal relations of two tropical lizards on Negros Island, Philippine Islands. Copeia 1966: 593-594.

AVERY, R. A. 1982. Field studies of body temperatures and thermoregulation. p. 93-166. In: C. Gans and P. H. Pough (eds.), Biology of the Reptilia, Vol. 12, Physiology C. Academic Press, London.

BENNETT, A. F. 1980. The thermal dependence of lizard behaviour. Anim. Behav. 28: 752-762.

BlANC, C. P. 1977. Reptiles Sauriens Iguanidae. Faune de Madagascar 45: 1-197.

FITCH, H. S. 1973. A field study of Costa Rican lizards. Univ. Kansas Sci. Bull. 50: 41-126.

Glaw, F. AND M. Vences. 1994. A Fieldguide to the Amphibians and Reptiles of Madagascar. 2nd ed. M. Vences \& F. Glaw Verlags GbR, Köln.

Gorman, G. C. AND S. Hillman. 1977. Physiological basis for climatic niche partitioning in two species of Puerto Rican Anolis (Reptilia, 
Lacertilia, Iguanidae). J. Herpetol. 11: 337-340.

Grant, B. W. AND A. E. DunhaM. 1990. Elevational covariation in environmental constraints and life histories of the desert lizard Sceloporus merriami. Ecology 71: 1765-1776.

HeRTZ, P. E., R. B. HuEY, AND R. D. STEVENSON. 1993. Evaluating temperature regulation by fieldactive ectotherms: the fallacy of the inappropriate question. Am. Nat. 142: 796-818.

HUEY, R. B. 1982. Temperature, physiology, and the ecology of reptiles. p. 25-91. In: C. Gans and F. H. Pough (eds.), Biology of the Reptilia, Vol. 12, Physiology C. Academic Press, New York.

HuEY, R. B. AND M. SLATKIN. 1976. Cost and benefits of lizard thermoregulation. Q. Rev. Biol. 51: 363-384.

HUEY, R. B. AND T. P. WeBSTER. 1976. Thermal biology of Anolis lizards in a complex fauna: the cristatellus group on Puerto Rico. Ecology 57: 985-994.

IKEUCHI, I., A. MORI, AND M. HASEgAwA. (in press) Natural history of Phelsuma madagascariensis kochi from a dry forest in Madagascar. Amphibia-Reptilia.

INGER, R. F. 1959. Temperature responses and ecological relations of two Bornean lizards. Ecology 40: 127-136.

JMP (version 3.2.2) 1997. SAS Institute Inc., Cary.

MORI, A. AND T. HIKIDA. 1993. Natural history observations of the flying lizard, Draco volans sumatranus (Agamidae, Squamata) from Sarawak, Malaysia. Raffles Bull. Zool. 41: 8394.

MORI, A. AND H. J. A. R. RANDRIAMAHAZO. 2002. Foraging mode of a Madagascan iguanian lizard, Oplurus cuvieri cuvieri. Afr. J. Ecol. 40: 61-64.

MORI, A., K. ARAYA, AND T. HIKIDA. 1995. Biology of the poorly known Bornean lizard, Apterygodon vittatus (Squamata: Scincidae): an arboreal ant-eater. Herpetol. Nat. Hist. 3: 1-14.

Mori, A., I. IKEUCHI, AND M. HASEGAWA. (in press). Herpetofauna of Ampijoroa, Ankarafantsika Strict Nature Reserve, a dry forest in northwestern Madagascar. Herpetol. Nat. Hist. 10.

RANDRIAMAHAZO, H. J. A. R. 1998. Activity temperatures in Oplurus cyclurus, Oplurus cuvieri and Zonosaurus laticaudatus and resting metabolic rates in the latter two species. Amphibia-Reptilia 19: 215-220.

RANDRIAMAHAZO, H. J. A. R. 2000. Sexual size dimorphism in the lizard Oplurus cuvieri cuvieri (Squamata, Opluridae) from Madagascar. Afr. Zool. 35: 287-293.

RANDRIAMAHAZO, H. J. A. R. AND A. MORI. 1999. Spatial utilization and social interactions in Oplurus cuvieri cuvieri (Squamata, Opluridae) in Madagascar. Jpn. J. Herpetol. 18: 57-65.

RANDRIAMAHAZO, H. J. A. R. AND A. MORI. 2001. Egg-laying activities and reproductive traits in females of Oplurus cuvieri cuvieri. J. Herpetol. 35: 209-217.

RAZAFY, F. L. 1987. La Reserve Forestière d'Ampijoroa: son modèle et son bilan. Unpublished master's thesis. Mémoire de fin d'études, Univeristé de Madagascar. Antananarivo.

RUIBAL, R. 1961. Thermal relations of five species of tropical lizards. Evolution 15: 98-111.

RUMMERY, C., R. SHINE, D. L. HOUSTON, AND M. B. THOMPSON. 1994. Thermal biology of the Australian forest dragon, Hypsilurus spinipes (Agamidae). Copeia 1994: 818-827.

SHINE, R. AND T. MADSEN. 1996. Is thermoregulation unimportant for most reptiles? An example using water pythons (Liasis fuscus) in tropical Australia. Physiol. Zool. 69: 252-269.

StatView (version 5.0) 1998. SAS Institute Inc., Cary.

TANAKA, S. 1986. Thermal ecology of the forestdwelling agamid lizard, Japalura polygonata ishigakiensis. J. Herpetol. 20: 333-340.

URANO, E., S. YAMAGISHI, A. ANDRIANARIMISA, AND S. ANDRIATSARAFARA. 1994. Different habitat use among three sympatric species of couas Coua cristata, C. coquereli, and C. ruficeps in western Madagascar. Ibis 136: 485-487.

WiLLIAMS, E. E. 1983. Ecomorphs, faunas, island size, and diverse end points in island radiations of Anolis. p. 326-370. In: R. B. Huey, E. R. Pianka, and T. W. Schoener (eds.), Lizard Ecology, Studies of a Model Organism. Harvard University Press, Cambridge.

Accepted: 19 November 2004 